\title{
Las primeras sociedades protectoras de animales en Argentina contra los espectáculos de la barbarie y la crueldad [Rosario y Buenos Aires en el último cuarto del siglo XIX]
}

Resumen: Este artículo se propone abordar los comienzos del proteccionismo animal en Argentina como un ejercicio imprescindible para una mejor comprensión del actual auge de los derechos animales. Para eso, se trabajará con las dos primeras experiencias del proteccionismo en el país: Rosario y Buenos Aires, prestando especial atención a su conformación societaria y al modo de entender el maltrato animal que predominaba en ellas. Así, se observará en ambas una marcada presencia elitista con amplia participación extranjera y una noción de maltrato animal circunscripta a la tracción a sangre y la tauromaquia como espectáculos desagradables de la barbarie colonial.

Palabras clave: proteccionismo, animales, corridas de toros, tracción a sangre, siglo XIX.

\section{The first animal protection societies in Argentina against the spectacles of barbarism and cruelty [Rosario and Buenos Aires in the last quarter of the 19th century]}

Abstract: This paper aims to address the beginnings of animal protectionism in Argentina as an essential exercise to better understand the current boom in animal rights. The focus will be on the first two experiences of protection in the country: Rosario and Buenos Aires, paying particular attention to their societal makeup and understanding the animal abuse that predominated there. Thus, it will observe a significant elitist presence in both, with broad foreign participation and a notion of animal abuse restricted to blood traction and bullifighting as unpleasant spectacles of colonial barbarism.

Keywords: protectionism, animals, bullifights, blood traction, 19th century.

\section{As primeiras sociedades de proteção animal da Argentina contra os espetáculos da barbárie e da crueldade [Rosário e Buenos Aires no último quartel do século XIX]}

Resumo: Este artigo tem como objetivo abordar o início da proteção animal na Argentina como um exercício essencial para uma melhor compreensão do atual boom dos direitos dos animais. Para isso, trabalharemos com as duas primeiras experiências de proteção animal no país: Rosario e Buenos Aires, prestando atenção especial à sua composição social e à maneira de entender o abuso de animais que nelas predominava. Assim, uma presença elitista marcante será observada em ambas, com ampla participação estrangeira e uma noção de abuso de animais circunscrita à tração animal e às touradas como espetáculos desagradáveis da barbárie colonial.

Palavras-chave: proteção animal, animais, touradas, tração animal, século XIX.

Cómo citar este artículo: Carolina Andrea Piazzi y Gonzalo Luis Corti, "Las primeras sociedades protectoras de animales en Argentina contra los espectáculos de la barbarie y la crueldad [Rosario y Buenos Aires en el último cuarto del siglo XIX]", Trashumante. Revista Americana de Historia Socia/18 [2021]: 100-123.

DOI: 10.17533/udea.trahs.n18a05

Fecha de recepción: 11 de junio de 2020

Fecha de aceptación: 15 de octubre de 2020

Carolina Andrea Piazzi: Doctora en Humanidades y Artes por la Universidad Nacional de Rosario. Investigadora Adjunta del Consejo Nacional de Investigaciones Científicas y Técnicas [CONICET]. ORCID: 00000003-3900-6234.

Correo electrónico: piazzi@ishir-conicet.gov.ar

Gonzalo Luis Corti: Estudiante de doctorado en Derecho en la Universidad Nacional del Litoral. Prosecretario en el Ministerio Público de la Acusación en la Unidad Fiscal de San Justo, Poder Judicial de la Provincia de Santa Fe.

- Correo electrónico: gonzicorti@gmail.com 


\title{
Las primeras sociedades protectoras de animales en Argentina contra los espectáculos de la barbarie y la crueldad [Rosario y Buenos Aires en el último cuarto del siglo XIX]
}

\author{
Carolina Andrea Piazzi y Gonzalo Luis Corti \\ Introducción
}

En el presente trabajo coinciden dos preocupaciones exploratorias en torno a la Derecho que estudia el recorrido histórico y normativo que tuvo la subjetivación jurídica de los animales no humanos en el campo del derecho penal argentino; por la otra, la visión de una historiadora dedicada, recientemente, a examinar desde el prisma de la historia de la justicia la preocupación en torno a la naturaleza. El punto de encuentro de ambas pesquisas fue indagar en el rol de las sociedades protectoras de animales de Rosario y Buenos Aires, las primeras aparecidas en Argentina, ${ }^{2}$ a fin de reconstruir cierto clima de ideas tendiente a la protección animal hacia fines del siglo XIX, que redundaría en la sanción de las primeras leyes nacionales proteccionistas. ${ }^{3}$

1. Denominada así por Mónica B. Cragnolini para señalar la convergencia de diversos campos disciplinarios de las humanidades en torno a los "estudios críticos de los animales" o animal studies. Véase Mónica B. Cragnolini, "Extraños animales: la presencia de la cuestión animal en el pensamiento contemporáneo”, Revista Latinoamericana de Estudios Críticos Animales 2 (2014): 15-33. El punto de partida de esta preocupación estaría ubicado en los movimientos de liberación animal de los años 70, cuando se comenzaron a cuestionar los límites entre lo humano y lo animal, principalmente a partir de las obras de Peter Singer y Tom Regan, quienes introdujeron en la discusión académica, y con gran fuerza, el tema de los derechos animales, lo que abrió un debate que continúa hasta el día de hoy, aunque siempre desde el plano de la ética.

2. La de Rosario precedió a la de Cuba (denominada Sociedad de Animales y Plantas), que se encuentra entre las primeras en América Latina. Véase Reinaldo Funes Monzote, "Facetas de la interacción con los animales en Cuba durante el siglo XIX: los bueyes en la plantación esclavista y la Sociedad Protectora de Animales y Plantas", Signos Históricos 8.16 (2006): 80-110. El libro de Silvia Urich es la revisión más detallada sobre el tema para el caso de Argentina, véase Silvia Urich, Los perritos bandidos: la protección de los animales de la Ley Sarmiento a la Ley Perón (Temperley:Tren en Movimiento, 2015).

3. La perspectiva jurídica del proteccionismo animal es analizada por Gonzalo Luis Corti en su tesis 
El proteccionismo animal cuenta con una profusa bibliografia proveniente de diversos campos disciplinares que no sería posible abordar aquí; sin embargo, el estado de la cuestión que se ha construido recupera aportes significativos para el enfoque que se pretende desarrollar. Si bien el interés se centra en los campos legal y judicial, la reconstrucción realizada examina aristas puntuales del proteccionismo previas a la sanción de la primera ley nacional de maltrato animal y que ofrecen una lectura más antropologizada y sociocultural de fines del siglo XIX. Se podría decir que la pregunta que este trabajo intenta responder es: ¿cuáles fueron las motivaciones que inauguraron la preocupación por el maltrato animal en el país y qué se entendía por tal en aquel entonces?

Tal vez de manera temprana para la historiografia, y desde una historia sociocultural, Maurice Agulhon publicó un artículo sobre la protección animal en Francia en el que recupera la primera ley sancionada al respecto, la ley Grammont de 1850, cuyo contexto y fundamentos sirven de encuadre para el caso de las sociedades protectoras argentinas. ${ }^{4}$ La cuestión de la minimización pública de la violencia y la crueldad sangrienta contra los animales aparece como parte de la sensibilidad burguesa del siglo XIX, la cual han reflejado, por ejemplo, las producciones sobre la vida privada y la relación con animales domésticos. ${ }^{5}$

La penalización del maltrato animal, primero, y el posterior reconocimiento de derechos a animales no humanos generaron una gran producción dentro del ámbito del Derecho, ${ }^{6}$ que incluyó la aparición del Derecho Animal, y un acalorado debate sobre las fronteras entre lo animal y lo humano, del que también ha hecho eco la antropología de la naturaleza, con las contribuciones fundamentales de María Carman. ${ }^{7}$

El trabajo se organiza en dos partes principales. En la primera, se retratan brevemente las dos protectoras abordadas, pues, para comprender lo que se entendía por maltrato animal, resulta imprescindible conocer quiénes y cómo eran los que se ocupaban de combatirlo. El asociacionismo en pos de la protección animal fue

doctoral (en curso al momento de la publicación de este artículo).

4. Maurice Agulhon, "Le sang des bêtes. Le problème de la protection des animaux en France au XIXème siècle”, Romantisme 11.31 (1981): 81-110.

5. Puede verse el abordaje que hace José Pedro Barrán del caso uruguayo: José Pedro Barrán, Historia de la sensibilidad en el Uruguay, t. 2 (Montevideo: Facultad de Humanidades y Ciencias / Ediciones de la Banda Oriental, 1990).

6. El trabajo de Christopher Stone fue pionero en esta línea.Véase Christopher Stone, “¿Los árboles deberían tener legitimidad procesal? Hacia un reconocimiento de los derechos legales de los objetos naturales", Derecho ambiental y justicia social, Garrett Hardin y otros (Bogotá: Siglo del Hombre Editores / Pontificia Universidad Javeriana, 2009) 137 ["Why Trees Should Have Legal Standing”, Los Angeles Times, 1974]. Remitimos también a Eugenio Raúl Zaffaroni, La Pachamama y el humano (Buenos Aires: Ediciones Madres de Plaza de Mayo, 2012); María Valeria Berros y otros, "La mirada jurídica sobre los animales: un análisis de su estatuto en el derecho privado argentino", Revista de Derecho de la Pontificia Universidad Católica de Valparaíso 48.1 (2017): 79-101.

7. María Carman, Las fronteras de lo humano: cuando la vida humana pierde valor y la vida animal se dignifica (Buenos Aires: Siglo XXI Editores, 2017). 
parte de la proliferación de sociedades constituidas, hacia mediados del siglo XIX, bajo la premisa de la unión libre de sus miembros a favor de un objetivo en común, que podía ser tanto en beneficio directo de los participantes, como con propósitos de índole filantrópico. ${ }^{8}$

En la segunda mitad del trabajo se describe concretamente qué entendían por maltrato animal las sociedades protectoras durante la época en estudio. En este sentido, se analizan más detenidamente los dos escenarios de maltrato que más energía concentraban entre los proteccionistas de la época: los espectáculos taurinos y la tracción a sangre. A través de las particularidades y connotaciones de cada uno de estos casos se busca completar someramente el retrato del proteccionismo animal de la sociedad rioplatense de fines del siglo XIX.

\section{Formación de las sociedades protectoras de Rosario y Buenos Aires}

Es normal escuchar, o incluso leer, que la primera protectora de animales en Argentina fue la fundada en Buenos Aires en el siglo XIX. Esto no es del todo cierto, o por lo menos requiere de algunas aclaraciones, las cuales se pretende resumir en algunos párrafos antes de comenzar el análisis.

En julio de 1871 se publicó en el diario La Capital de Rosario una nota sobre la necesidad de formar una sociedad protectora de animales. Esto se escribía un año después de que se aprobaran los estatutos de la plaza de toros de esa ciudad. Al poco tiempo de publicado el artículo, se registraron las primeras reuniones de proteccionistas en la ciudad, las cuales condujeron a la redacción, en septiembre de ese año, del Reglamento de la Sociedad Protectora de Animales de Rosario (SPAR), firmado por más de 50 socios fundadores.

Trescientos kilómetros al sudeste y ocho años después, daría sus primeros pasos en la ciudad de Buenos Aires la Sociedad Argentina Protectora de los Animales (SAPA). Las reuniones preparatorias tuvieron como sede la iglesia evangélica metodista de la ciudad porteña y el 21 de agosto de 1879 derivaron en el nombramiento de las primeras autoridades de la protectora. Las bases y reglamentos demorarían un poco más en ser redactados; fue hasta 1881 cuando se sancionaron, con la correspondiente designación de sus autoridades. Sin perjuicio de lo relatado, ninguna de las dos protectoras estaba formalmente constituida, y es en este sentido que se abre la discusión sobre la preexistencia de una u otra sociedad.

La primera en ser reconocida como persona jurídica fue la SAPA, mediante el decreto del presidente de la nación con fecha 11 de abril de 1882, gracias a las gestiones de Domingo Faustino Sarmiento, quien sería el primer presidente oficial

8. Pilar González Bernaldo de Quirós, "Sociabilidad y regímenes de lo social en sociedades postimperiales: Una aproximación histórica a partir del caso argentino durante el largo siglo XIX", Sociabilidades en la historia: actas del VIII Congreso de Historia Social de España, Tarragona, 16 al 18 de abril de 2015, coords. Santiago Castillo y Montserrat Duch i Plana (Madrid: Catarata, 2015) 213-234; Roberto Di Stefano y otros, De las cofradías a las organizaciones de la sociedad civil. Historia de la iniciativa asociativa en Argentina, 1776-1990, coords. Elba Luna y Elida Cecconi (Buenos Aires: Edilab, 2002). 
de dicha protectora. Por su parte, la SPAR se tomó algo más de tiempo para la constitución de su personería jurídica, lo que finalmente se concretó durante la presidencia de William Barnett, el 11 de octubre de 1886, por decreto del Ejecutivo de la provincia de Santa Fe, cuatro años y medio después de la porteña y 15 después de su propio inicio de actividades.

Con base en lo anterior, se pueden suscitar diferencias respecto a la consideración de cuál fue la primera protectora de animales en fundarse en el país. Dependerá si se tiene en cuenta la fundación de hecho o la constitución formal como persona jurídica. En definitiva, no es intención de este trabajo tomar una posición en ese sentido, sino simplemente destacar los hechos históricos más relevantes en la formación de ambas protectoras, con lo cual se deja de lado la discusión sobre el precedente proteccionista en el país.

\subsection{Composición societaria}

La SPAR, como se señaló, fue fundada en septiembre de 1871. ${ }^{9}$ En su reglamento, de solo siete breves artículos, se estipulaba que cualquier persona podría ser miembro al firmar dicho reglamento y abonar una mensualidad de un peso boliviano.

La lista de los miembros fundadores incluye 59 nombres con base en los que intentaremos confeccionar una suerte de perfil sobre quiénes eran esos hombres interesados en promover una sociedad de este tipo. ${ }^{10}$ La figura más destacada en el momento fundacional fue la de Cecilio Echeverría, quien fuera el primer presidente de la Sociedad, pero no su promotor, ya que este papel lo desempeñaba el reverendo Thomas Wood, de quien se hablará más adelante (Figura 1). ${ }^{11}$ Echeverría ocupaba el cargo de capitán del puerto de Rosario ${ }^{12} \mathrm{y}$, a partir de su correspondencia, es posible conocer su vínculo con los políticos más prominentes de la época: se adscribió al mitrismo; mantuvo relación con Sarmiento; fue corresponsal de J.A. Roca en Rosario y miembro honorario de la SAPA.${ }^{13}$ Entre su actividad social se cuenta, además de la Sociedad Protectora, la membresía a la Comisión de la Biblioteca Popular de Rosario (1872).

9. "Expedientes varios", 1886. Archivo General de la Provincia de Santa Fe (AGPSF), Santa Fe, Gobierno, t. 82, n. 28, ff. 544-546.

10. "Reglamento y lista de sus miembros fundadores", 16 de septiembre de 1871.Archivo Histórico Provincial "Dr. Julio Marc" (AHPRJM), Rosario, Archivo Jefatura Política de Rosario, t. 1871B.

11. Debajo de la imagen se lee: "Mister Wood lo dijo, todos somos animales. Este precedente ha producido la confusión de clases sociales, y como consecuencia, el antagonismo entre protectores y protegidos. Después del combate que averigüe Dios quién son los protectores". La Cabrionera (Rosario) 3 de diciembre de 1871.

12. La capitanía del puerto supervisaba las entradas y salidas de mercancías. El capitán era también comandante del resguardo y dependía del administrador de la aduana.

13. "Correspondencia Cecilio Echeverría". AHPRJM, Rosario, Documentos manuscritos, 18701904. 


\section{Ina Pabrionera.}

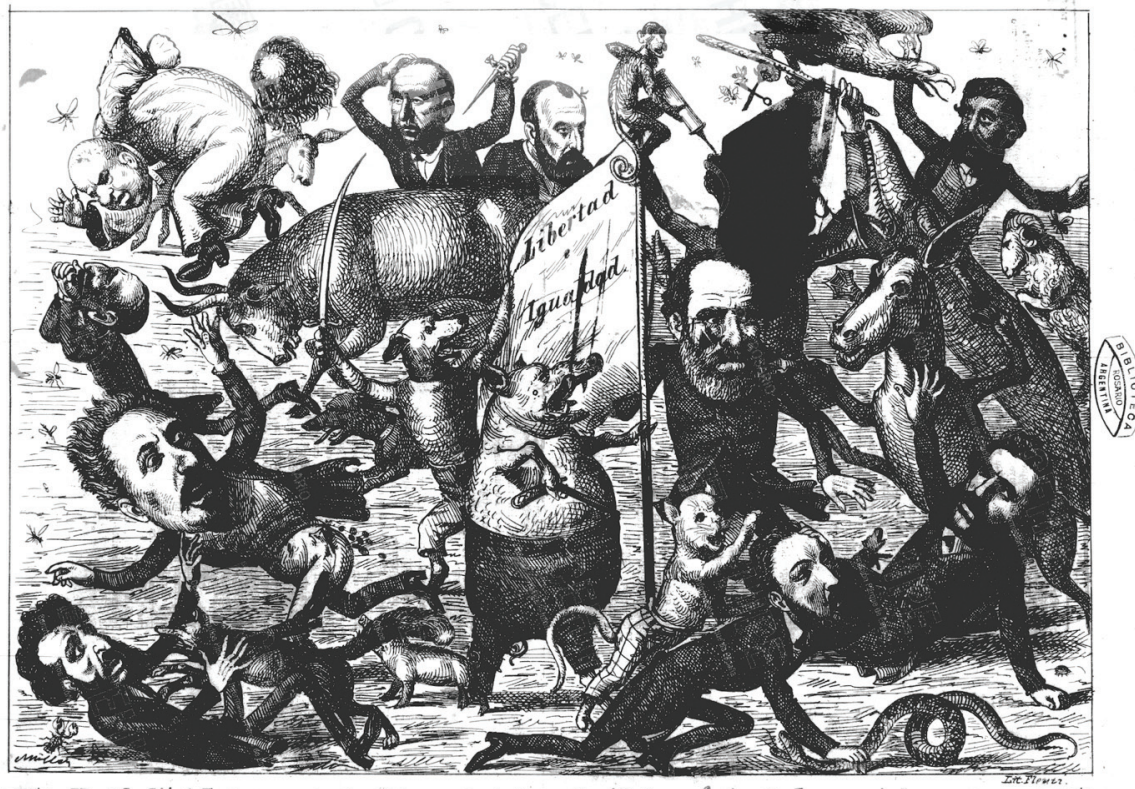

Mister.Wood lo dijo, todos samos animales - Este precedente ha producido la conf usion de clases sociales, y como conseckencia el antagonismo entre protectores y protejidas - 7 espues del combate que arerigue Dios quien son Tos proteotores. -

Fuente: La Cabrionera (Rosario) 3 de diciembre de 1871.

Del análisis de los 59 nombres que firmaron el reglamento de la SPAR, se desprende una composición variada de hombres que compartían, sobre todo, intereses económicos; se trataba de comerciantes y accionistas de Ferrocarriles Argentinos (FFCC), de la Bolsa de Comercio o del Banco Provincial de Santa Fe (con apellidos tales como Escayola, Lejarza, Machaín, Castellanos, Recagno, Rezia y Sala, Tietjen). ${ }^{14}$

En relación con su origen, entre los nombres cuyo perfil se pudo confirmar había 13 extranjeros (ingleses, españoles, italianos, alemanes, estadounidenses) y ocho argentinos. Predominaban los ingleses, con una marcada tendencia anglicana y metodista, bajo los auspicios del pastor Thomas Wood, lo cual amerita un apartado especial. Como lo ha mostrado Paula Seguier, la "presencia de ingleses en el puerto

14. No se han podido identificar con certeza todos los 59 nombres del listado. Los perfiles fueron realizados a partir de bibliografia diversa, principalmente: Gabriela Dalla Corte Caballero, Lealtades firmes. Redes de sociabilidad y empresas: la "Carlos Casado S.A." entre la Argentina y el Chaco paraguayo (1860-1940) (Madrid: Consejo Superior de Investigaciones Científicas, 2009); Vicente Osvaldo Cutolo, Nuevo diccionario biográfico argentino (1750-1930) (Buenos Aires: Elche, 1969); Centro de Estudios Genealógicos e Históricos de Rosario, Boletín no. 1 - año 1 (2003); Centro de Estudios Genealógicos e Históricos de Rosario, Boletín no. 2 - año 2 (2004). 
de Rosario creció notablemente con la creación del poderosísimo FFCC Central Argentino, cuyas obras se iniciaron en 1863", mientras que pocos años después, en 1868, se creaba la capellanía de San Bartolomé, “una de las más antiguas de la provincia". ${ }^{15}$ Entre los apellidos más resonantes de los miembros fundadores de la SPAR estaban personajes del ámbito social, como Ovidio Lagos, y funcionarios con cargos en la administración pública de la ciudad, como Coll, Monguillot, Piñero, Rueda y Wheelwright.

El caso de la protectora porteña tiene muchas similitudes con el de la rosarina en lo que a composición societaria se refiere. También en la capital nacional se contaba con una fuerte presencia anglosajona entre los miembros, pues en las listas del último cuarto del siglo XIX, entre 25\% y 35\% de los apellidos eran de origen angloparlante. ${ }^{16}$ Esto no debe sorprender si se tiene en cuenta que las sociedades pioneras en el mundo fueron la Royal Society for the Prevention of Cruelty to Animals, fundada en Londres, y la de Nueva York, la American Society for the Prevention of Cruelty to Animals, las cuales fueron ejemplos a imitar y puntos de referencia para la evaluación interna de la actividad de la SAPA.

Sin embargo, hay algo que es importante destacar en la estructura de la protectora porteña, y tiene que ver con la fuerte selectividad social que impregnó su conformación, principalmente en sus primeros años de vida. Junto con la ya destacada participación de Domingo Faustino Sarmiento, la lista de miembros de la SAPA, en el periodo en estudio, incluyó también al general Bartolomé Mitre y a otras personalidades ilustres de la época. ${ }^{17}$ Se puede apreciar preliminarmente que la composición societaria de esta asociación era un tanto encumbrada, más todavía si se tiene en cuenta que, por reglamento, para la admisión de una persona como nueva socia, esta debía ser presentada por un miembro activo y su aprobación era sometida a consideración de la Comisión Directiva, requisito al que luego se agregaría la responsabilidad solidaria de los presentadores por los compromisos y obligaciones de los presentados.

La SAPA procuraba inicialmente estar integrada por los sectores más elevados de la sociedad porteña, lo que se entiende mejor si se toma en cuenta el costo que implicaba la membresía. En las bases y el reglamento de la asociación se estableció que la cuota mensual (para mayores de edad) era de 10 pesos mensuales y que, además, para recibir su diploma, el postulante debería donar al momento de su inscripción "la suma que tenga por conveniente, no bajando de veinte pesos". ${ }^{18}$

15. Paula Seiguer, "Jamás he estado en casa". La Iglesia Anglicana y los ingleses en la Argentina (Buenos Aires: Editorial Biblos, 2017).

16. Por ejemplo, en 1883 se observa un 32\% de apellidos de origen anglosajón. Véase Sociedad Argentina Protectora de los Animales (SAPA), "Segundo informe anual" (Buenos Aires, 1883). Mientras que en 1891 encontramos un 29\% de apellidos de la misma raíz.Véase SAPA, "Décimo informe anual" (Buenos Aires, 1891).

17. Mitre y Sarmiento fueron presidentes de la nación de 1862 a 1868 y de 1868 a 1874, respectivamente.

18. SAPA, "Bases y reglamento de la Sociedad Protectora de Animales" (Buenos Aires, 1881) 7. 
Este dato, analizado a la luz del hecho de que el salario promedio de un obrero no calificado en Buenos Aires para esa época rondaba los 120 pesos, ${ }^{19}$ o que un carrero cobraba dos pesos diarios, ${ }^{20}$ da una idea bastante completa de quién podía ser miembro activo de la Protectora.

Como se pudo ver hasta aquí, las protectoras de Rosario y Buenos Aires se formaron en fechas relativamente cercanas, en contextos similares y con una composición que mostraba un cierto elitismo en su admisión, tal vez más fuerte en el caso porteño. En una y otra se puede observar una gran influencia de algunas personalidades destacadas de la época, lo que reforzaba aún más lo encumbrado de su posicionamiento.

A su vez, se detecta un gran número de integrantes extranjeros en ambas sociedades, principalmente de origen anglosajón, lo que no debe extrañar si se tiene en cuenta el intenso vínculo que las protectoras tuvieron en sus inicios con la Iglesia metodista, panorama que se intentará plasmar brevemente en el apartado que sigue.

\subsection{Sarmiento, católicos, metodistas y masones unidos por la protección animal}

Entre las décadas de 1860 y 1880 tuvo lugar una profundización en el proceso de laicidad pública, y la provincia de Santa Fe no fue ajena al mismo. ${ }^{21}$ El estudio de este proceso ha tenido más en cuenta lo sucedido en las colonias o las disputas entre el gobierno provincial y la Iglesia católica, por las sucesivas "leyes laicas", mientras que lo ocurrido con las iglesias protestantes en la ciudad de Rosario, por ejemplo, no recibió la misma atención. En lo que interesa directamente a este artículo, los trabajos que existen provienen del seno de la Iglesia metodista, ${ }^{22}$ y permiten ubicar mínimamente a quien fue el impulsor de la SPAR: el reverendo Thomas Wood.

Wood fue una figura central en la formación de dicha Sociedad. Llegó a la ciudad en 1870, con la encomienda de hacerse cargo de la Iglesia metodista, donde

19. Eduardo Martín Cuesta, "Precios y salarios en Buenos Aires durante la gran expansión (1850-1914)", Revista de Instituciones, Ideas y Mercados 56 (2012): 168.

20. Diarios de Sesiones de la Cámara de Diputados de la Nación (Buenos Aires: Congreso de la Nación, 1891) 377.

21. Diego A. Mauro, "Procesos de laicización en Santa Fe (Argentina): 1860-1900. Consideraciones sobre la 'Argentina liberal y laica", Revista de Indias 74.261 (2014): 539-560.

22. Guillermo Tallon, Historia del metodismo en el Río de la Plata, 1836-1936: un panorama histórico de la Iglesia Metodista Episcopal en la Argentina, Uruguay y Paraguay, durante los cien años transcurridos desde su iniciación hasta nuestros días (Buenos Aires: Imprenta Metodista, 1936); Norman Rubén Amestoy, "El reformismo social metodista en el Río de la Plata y sus raíces ideológicas", Cuadernos de Teología 20 (2001): 343-360; Norman Rubén Amestoy, “Thomas Wood y su presencia en el Río de la Plata", Invenio. Revista de Investigación Académica 12.22 (2009): 29-41; Norman Rubén Amestoy, "Sociedades metodistas y pensamiento científico en el Río de la Plata (1867-1901)", Estudios de Historia Moderna y Contemporánea (2009): 1-25. 
desempeñó una intensa actividad pastoral y docente entre 1870 y $1876 .{ }^{23}$ Entabló vínculos con el entonces presidente de la nación, Domingo Faustino Sarmiento, por quien fue designado corresponsal del Observatorio de Córdoba (fundado por el mismo Sarmiento) en 1872, y nombrado cónsul de Estados Unidos en Rosario en el mismo año.

Hacia fines de siglo XIX y comienzos del siglo XX, el metodismo desarrolló una importante obra en el ámbito educativo que acompañó las iniciativas de los gobiernos liberales de la época, y en particular la obra de Sarmiento, con quien el metodismo argentino había estrechado lazos de camaradería y vinculación a través de las logias masónicas a las que pertenecían Sarmiento y los principales referentes metodistas. ${ }^{24}$

Estos vínculos también pueden observarse en gran medida en el caso de la SAPA. De hecho, como ya se mencionó, la primera reunión en 1879, en la que se dispuso la creación de la Sociedad, tuvo lugar en una iglesia metodista de la ciudad de Buenos Aires, y fue promovida por un conocido pastor de ese credo protestante, el reverendo Juan Francisco Thomson, quien fuera un influyente miembro de la protectora a lo largo del fin de siglo, con un derecho de voz preferente.Además, es importante recordar que Sarmiento, si bien no fue miembro fundador de la SAPA, fue el primer gran impulsor de su crecimiento y reconocimiento, ${ }^{25}$ principalmente a través de sus gestiones como presidente de la Sociedad, cargo que ocupó entre 1882 y 1885, momento en que anunció el fin de su ciclo por resultarle "una carga pesada la prolongación en estas funciones". ${ }^{26}$ Se observa entonces que la logia masónica también tuvo cabida en la protectora porteña, y llegó incluso a unir bajo un mismo estandarte a Sarmiento y a Mitre, quienes fueron hermanos en la protectora y adversarios en la política partidaria.

De manera paralela a este lazo con la Iglesia metodista, la SAPA mantuvo algunas asperezas con la religión católica, cuyo punto más alto tuvo lugar en 1890, cuando el diario oficial del arzobispado en la República Argentina, titulado "La voz de la Iglesia", destinó su edición del 12 de abril a criticar duramente un libro sobre cuidados a los caballos publicado por la protectora. Dicha edición reprobaba el "empeño en bestializar al hombre y en humanizar a las bestias" 27 y centraba todas sus burlas en el doctor Albarracín, quien, lejos de ignorar el hecho, contestó con una nota al arzobispo que fue publicada a su vez en el diario La Prensa y que, entre otras cosas, sostenía que la Iglesia católica no se encontraba en posición de mofarse de una sociedad como la SAPA.

23. Sobre el metodismo en Rosario y la presencia de Thomas Wood remitimos a Tallon y a Amestoy, "El reformismo social".

24. Véase Daniel Bruno, "Abordaje y periodización para una historia del metodismo en Argentina", Revista Evangélica de Historia 7 (2012): 11-44.

25. Urich.

26. SAPA, "Cuarto informe anual” (Buenos Aires, 1885) 7.

27. SAPA, "Noveno informe anual” (Buenos Aires, 1890) 48. 
De acuerdo con lo detallado en los párrafos anteriores, no quedan dudas de que los vínculos con la Iglesia metodista fueron uno de los principales denominadores comunes entre las protectoras de Rosario y Buenos Aires en el siglo XIX. Este rasgo, junto con los componentes étnicos y de clase antes descritos, ayuda a entender mejor cómo concebían el maltrato animal estas asociaciones y qué acciones consideraban que eran más importantes para combatirlo.

\section{Los protegidos contra el maltrato, la crueldad y la barbarie}

El trabajo de Maurice Agulhon conduce directo a la interrogante de qué se entendía por "maltrato animal" en el siglo XIX.$^{28}$ Cabe aclarar que las ideas proteccionistas no surgieron en dicho siglo, ya que existen antecedentes en sociedades puritanas del siglo XVI, aunque fue hasta la Revolución Industrial cuando aparecieron las primeras sociedades protectoras como tales. ${ }^{29}$ Existe una coincidencia en que los principales sujetos de protección durante esa época fueron dos: los animales de tiro (y aquí quienes estaban bajo la mira eran los carreros) y los toros utilizados para los espectáculos taurinos en las plazas. ${ }^{30}$

Además de lo estipulado en los reglamentos y estatutos de las protectoras, otro registro que contiene información sobre lo que se consideraba como acciones de maltrato y crueldad animal fueron las disposiciones policiales y de seguridad pública (ordenanzas, leyes, reglamentos). En Rosario, la disposición más citada por los proteccionistas fue el artículo 33 del reglamento de policía de 1864, dedicado al "maltrato de animales": "Se prohíbe estropear a golpes todo animal de servicio; multa de dos pesos. Los agentes de Policía cuidarán de reprimir tan inhumano abuso, y que en los carros de carga no se conduzca más peso del que naturalmente pueden recibir los animales que tiren". ${ }^{31}$

En general, las medidas proteccionistas presentaban dos características; por un lado, su encuadre era claramente urbano, y por otro, apuntaban a evitar escenas de crueldad y maltrato asociadas a la barbarie. Quienes reclamaban ante estas situaciones - los miembros de las protectoras - pertenecían a cierto sector notable de la ciudad, que miraba con horror tanto el maltrato de los carreros hacia los animales

\section{Agulhon.}

29. Thomas G. Kelch, "A Short History of (Mostly) Western Animal Law: Part I", Animal Law Review 19.23 (2012): 23-62; Richard Holt, Sport and the British. A modern history (Oxford: Oxford University Press, 2009).

30. Las riñas de gallos fueron prohibidas a instancias de Albarracín, con la ley 2786.Véase Pedro Olgo Ochoa, "La riña de gallos, seducción de ricos y pobres", Todo es Historia 29 (1969): 28-36.

31. Reglamento de Policía. Registro Oficial de la provincia de Santa Fe, t. 4 (Santa Fe: Tipografía de la Revolución, 1889) 215-217. Una extensa ordenanza de 1888 penaba con una multa de dos a seis pesos golpear a un animal o tratarlo de forma brutal, hacer trabajar a animales lastimados o en estado de extrema delgadez, usar la picana, llevar más carga de la autorizada (carreros y tramways), causar dolor innecesario en la matanza de animales para consumo, incitar a peleas de perros u otros animales y desplumar aves vivas. Véase Ordenanza del 20 de abril de 1888 (Buenos Aires: Publicación Oficial, Cía. Sudamericana de Billetes de Banco, 1890) 256-259. 
de tiro, como la muerte y el derramamiento de sangre de los toros en las plazas. Se amparaban en un discurso, ya conocido, en torno a la barbarie y civilización:

La civilización de una Nacion exije que todos los séres útiles que en ella existan sean lejítimamente representados y protejidos. Si el hombre inhábil é incapaz de valerse por sí mismo, tiene su representación y leyes que le protejen. ¿Por qué no la ha de tener el irracional, que no puede darse razón de ninguno de sus actos? ${ }^{32}$

La cita se ajusta a lo señalado por Christopher Stone respecto a la homologación del animal con seres incapaces o inhábiles en el sentido de que ambos necesiten una figura "guardiana" o "protectora". ${ }^{33}$ Además, la frase contiene un concepto clave que forma parte fundamental del análisis del paradigma proteccionista del siglo XIX argentino: el concepto de civilización. No corresponde a este trabajo ahondar en la descripción de dicha noción, pero vale aclarar que no escapó a la SAPA la importancia que la misma revestía en la sociedad rioplatense de fines de siglo XIX, y mucho más si se tiene en cuenta el rol simbólico y fundacional de Domingo Faustino Sarmiento. ${ }^{34}$ Siempre que se hablaba de proteger a un animal, esto era asociado a los valores de una nación o sociedad civilizada, mientras que todo acto de maltrato era indudablemente relacionado con la barbarie de la que Argentina se pretendía deshacer. Es más, resulta muy significativo que en la asamblea de la SAPA de 1898 se reivindique a la abolición de las corridas de toros como uno de los logros de la Revolución de Mayo, así como en reiteradas veces se asoció esta práctica a la barbarie de la cultura española, a la que la obra de la SAPA sostiene que no permitirá que se vuelva.

\subsection{Espectáculos taurinos}

Las gestiones para construir una plaza de toros en Rosario se iniciaron a mediados de 1870, a instancias de José de Caminos — que había obtenido la concesión por parte de la provincia en enero de 1869-, quien la concedió a dos empresarios montevideanos, José Gambín y Santiago Ramos, a fin de que concretaran la obra. ${ }^{35}$

32. SAPA, "Cuarto Informe" 9.

33. Stone.

34. Sirva mencionar que cuando se habla de "civilización" se hace referencia menos a la idea de Norbert Elias, de regulación de las emociones individuales por medio de coerciones internas o externas que controlan las experiencias y los comportamientos de las personas, que a la representación antinómica civilización-barbarie trabajada por el propio Sarmiento y que contrapone los rasgos culturales de las urbes europeas, con sus instituciones y costumbres, a la cultura (inculta para dicho autor) de las comunidades originarias americanas. Véase Norbert Elias, El proceso de la civilización: investigaciones sociogenéticas y psicogenéticas (México: Fondo de Cultura Económica, 2015); Domingo Faustino Sarmiento, Facundo: ó, Civilización i barbarie en las pampas argentinas (París: Hachette y Cía., 1874).

35. "Expedientes varios", 1870. Archivo General de la Provincia de Santa Fe (AGPSF), Santa Fe, Gobierno, t. 35, leg. 17, ff. 1155-1165v. Según aparece en "Notas Importantes", la SPAR intentó comprar la concesión a Andrés González, quien figuraba como el organizador del evento en las publicidades de las corridas, sin conseguirlo. 
Ante la inminencia del inicio de las actividades, la SPAR comenzó a desplegar una serie de estrategias con el fin de lograr su suspensión y prohibición. En principio, se dirigió al gobierno provincial —en ese momento presidido por Simón de Iriondo - para:

Salvar el derecho de un peligro inminente que corre toda esta sociedad del Rosario a la cual se le va a ofrecer dentro de muy pocos días, el horrible y el más brutal espectáculo de una plaza de toros $[\ldots]$ para llevar a cabo la obra más a propósito para el embrutecimiento, la consiguiente ruina moral y material de un pueblo inocente. ${ }^{36}$

La respuesta del gobierno (en la vista fiscal) fue que, además de no considerar inmorales las corridas de toros, la resolución del pedido no debía ser gubernativa sino policial. Echeverría, al frente de la SPAR, intentó abrir un expediente criminal contra la empresa de la plaza de toros en el juzgado ordinario de Rosario, pero la respuesta del fiscal y del juez fue la misma. A pesar de que se manifestaban en contra de esos espectáculos sangrientos, perniciosos para la moral y las buenas costumbres, argumentaron que:

Son clasificados estos actos como simples contravenciones policiales sujetas a una pena correccional que se establece por las mismas. Tal es lo que dispone el Reglamento de Policía Urbana y Rural, en su artículo 33, y aun que él no es exactamente aplicable al caso que nos ocupa, a falta de otra disposición terminante al respecto, puede hacerse extensivo a él lo que el referido artículo estatuye (vista fiscal). ${ }^{37}$

Los proteccionistas insistían en que su reclamo era válido por ser de carácter constitucional, a partir de las leyes que consagraban la libertad de industria, "pero de industria lícita", y que, al considerar que la empresa de la plaza de toros realizaba una actividad que afectaba la moral pública y que había sido abolida por la mayoría de las naciones civilizadas europeas, debía prohibirse. Ante la apelación, nuevamente la respuesta fue que, a pesar de estar de acuerdo con los motivos moralistas de la Sociedad, la autoridad competente a la que debían recurrir era la policial. ${ }^{38}$

En febrero de 1872 se realizó la primera corrida, y en 1874 una ordenanza municipal prohibió las corridas de toros en la ciudad, ${ }^{39}$ aunque se sabe que continuaron realizándose. ${ }^{40}$

36. "Solicitudes varias", 1872. AGPSF, Santa Fe, Gobierno, t. 38, leg. 19, ff. 27 y ss.

37. "Cecilio Echeverría representando a la Sociedad Protectora de los Animales", 1872. AHPRJM, Rosario, Expediente penal, leg. 18, exp. 19.

38. La causa se extendió desde marzo de 1872 hasta diciembre de 1873, fecha en que fue archivada por el juez Peña.

39. Ordenanza del 14 julio 1874 (Buenos Aires: Publicación Oficial, Cía. Sudamericana de Billetes de Banco, 1890) 57.

40. María Gabriela Micheletti señala que en 1891 hubo un conflicto por la autorización municipal para las corridas de toros. Lo mismo sucedió con las prohibiciones referidas a las riñas de gallos, 
Este tipo de espectáculos podían asemejarse a lo que ocurría con el carnaval, en cuanto excesos que afectaban la moral pública. ${ }^{41}$ Las corridas dividieron a la élite rosarina: por un lado, estaban quienes, representados en la capital, publicitaban y aprobaban estos espectáculos, y por otro, los defensores del proteccionismo animal. Ambos argumentaban sus ideas en términos "civilizatorios": o iban en contra de sociedades civilizadas (proteccionistas) o formaban parte de las naciones civilizadas (pro corridas). ${ }^{42}$

La lucha contra las corridas de toros también marcó el paso de la SAPA porteña de fines del siglo XIX, pero con marcadas diferencias respecto al caso rosarino. La causa principal de estas disimilitudes tiene que ver mayormente con que las corridas de toros habían sido prohibidas bastante tiempo antes de la formación de la protectora, en 1822, por el entonces gobernador de Buenos Aires, Martín Rodríguez. ${ }^{43}$ Claro que esto no fue impedimento para que se intentaran organizar corridas de toros en la Buenos Aires finisecular en varias ocasiones; tales intentos pretendían ampararse en la pérdida de vigencia de la norma prohibitoria, con base en los cambios institucionales que habían ocurrido en el país desde 1822 hasta las últimas décadas del siglo XIX. Frente a estas tentativas, la SAPA mostró su más enérgica desaprobación; por ejemplo, en 1885, ante una noticia periodística sobre la solicitud de autorización para realizar una corrida de toros embolados (con los cuernos enfundados en cuero), Sarmiento envió una nota al intendente de Buenos Aires donde le pedía que "no hiciera lugar al espectáculo que se solicita,

las carreras de caballos y otros entretenimientos tradicionales arraigados en sectores populares. Para ampliar sobre el tema se remite a María Gabriela Micheletti, "Entre gauchos y gringos. Costumbres nacionales y extranjeras en Santa Fe (1880-1900)", Temas de Historia Argentina y Americana 16 (2010): 239-240, 245-247. El Coliseo Taurino se inauguró en la ciudad en 1899. Tomás Barrandeguy, "Toros, corridas y un coliseo imponente en pleno centro de Rosario", La Capital (Buenos Aires) 9 de febrero de 2020. https://www.lacapital.com.ar/la-ciudad/toroscorridas-y-un-coliseo-imponente-pleno-centro-rosario-n2563025.html (21/08/2020).

41. Por esos mismos años (1870), Ricardo Falcón ubica una campaña "moralizadora" respecto al carnaval. Algunos de los argumentos esgrimidos por los defensores del carnaval eran similares a los que planteaban en su defensa los accionistas de la empresa Plaza de Toros en cuanto que eran espectáculos "para todo el pueblo", el carnaval era una "fiesta para todos", y generaban fuentes de trabajo. Véase Ricardo Falcón, "La larga batalla por el carnaval: la cuestión del orden social, urbano y laboral en el Rosario del siglo XIX", Anuario de la Escuela de Historia. Segunda Época 14 (1990): 207-226. El empresario José de Caminos exponía argumentos similares a favor de las corridas:"atraer gran concurrencia y dar movimiento a muchos ramos del pequeño comercio que utiliza provechos y conveniencias. Las gentes que venden especies superfluas, los vehículos de todas clases que sirven para trasladar gran parte de la concurrencia; el número de personas que se emplean, el contacto de un crecido número de personas, todo esto refluye en provecho de las gentes pobres que utiliza a la sombra de estos espectáculos, y atrae población transeúnte de otras provincias y pueblos vecinos". Véase "Expedientes varios", 1870. AGPSF, Santa Fe, Gobierno, t. 35, leg. 17.

42. Una revisión de la situación de las corridas de toros puede verse en Ana Cecchi, "La ciudad timbera: juego, Estado y cultura en Buenos Aires, 1891-1932” (Tesis de doctorado en Historia, Universidad de San Andrés, 2016) 49-52.

43. Gilda Guerrero, “Toros en Buenos Aires”, Todo es Historia 26 (1969): 42-49. 
manteniendo así incólumes nuestras gloriosas tradiciones", a lo que el intendente Torcuato de Alvear respondió que le era "satisfactorio comunicarle" que había denegado tal permiso. ${ }^{44}$

Es importante aclarar que quien más énfasis ponía en la prohibición taurina en el seno de la SAPA era Sarmiento. Además de su conocido amor por los animales, esta lucha tenía como fundamento que el expresidente nacional veía en la tauromaquia una cabal manifestación de la cultura barbárica española que tanto ansiaba desterrar de la Argentina. Sin embargo, aun luego del alejamiento del famoso sanjuanino de la presidencia societaria en 1885, la SAPA continuó oponiéndose fervorosamente a las corridas de toros, pero ya más como una especie de vigía nacional y regional que se ocupaba de denunciar cualquier intento de corrida de toros que se presentase en el país o, también, en Montevideo.

Al igual que para toda la actividad de la SAPA en el último cuarto de siglo, la sanción de la ley 2786 de maltrato animal representó un gran incentivo y un fuerte instrumento legal para luchar contra las corridas de toros. Con esta herramienta en sus manos, la protectora modificó su estrategia protocolar por una más jurídica. En esto tuvo mucho que ver el hecho de que a Sarmiento le bastaba una carta para ejercer presión sobre las autoridades, mientras que el poco ilustre Albarracín necesitaba mayormente acudir a los tribunales para lograr los propósitos proteccionistas. Lo cierto es que la estrategia judicial le dio algunas alegrías a la SAPA, al lograr dictámenes favorables de la Procuración General respecto a la plena aplicabilidad de la ley de maltrato animal en la prohibición de las corridas de toros en 1892, ante un intento de lidia en Rosario, ${ }^{45}$ y en 1898, ante otro en Guaymallén, Mendoza, ${ }^{46}$ conclusiones que tanto Pellegrini como Uriburu convirtieron en decretos presidenciales.

En fin, así fue como la SAPA mantuvo viva la lucha de Sarmiento contra las corridas de toros, mientras se jactaba de ser la guardiana de, como diría el prócer sanjuanino, "una de las más preciosas conquistas de nuestra Independencia; la abolición de las corridas de toros". ${ }^{47}$

\subsection{Tracción a sangre}

El casco céntrico de la ciudad de Rosario vio hacia la década de 1870 la llegada de tramways instalados por burgueses locales. Esta nueva forma de transporte llevó a reglamentar su uso por parte de los trabajadores del servicio, transeúntes y pasajeros. Uno de los conflictos que se desató con este avance modernizador fue, precisamente, por el tipo de tracción que se utilizaba: caballos, generalmente mal alimentados, que debían soportar sobrecargas de peso, además del maltrato

44. SAPA, "Cuarto Informe" 34-36.

45. SAPA, "Undécimo informe anual” (Buenos Aires, 1892) 6-7.

46. SAPA, "Decimoséptimo informe anual” (Buenos Aires, 1898) 6.

47. SAPA, "Cuarto Informe" 34. 
propiciado por los cocheros, "esto último generaría incomodidad entre los usuarios y enfrentamientos concretos con la Sociedad Protectora de Animales". ${ }^{48}$ En los primeros años del siglo XX, la tracción a sangre comenzaría a ser reemplazada por la eléctrica.

Así, además de ocuparse de intentar evitar las corridas de toros, la otra tarea a la que se abocaron los proteccionistas, y que ofició de motivación inicial para la creación de la Sociedad, fue prevenir y castigar los maltratos a los que los carreros sometían a los caballos y bueyes de tiro. En la nota dirigida al jefe político que acompañó la presentación del reglamento y de los miembros fundadores, los argumentos que se presentaron, sin ser explícitos sobre la tracción animal, se dedicaban en extenso a resaltar la necesidad de difundir y hacer cumplir las disposiciones vigentes contra la crueldad animal, principalmente por parte de los comisarios, tras lo cual solicitaban autorización para realizar detenciones:

Sin alguna autorización oficial, los esfuerzos de los vigilantes de la Sociedad serían burlados y hasta cierto punto inútiles. Mas con poder de arrestar a cualquier hombre en el acto de cometer una crueldad ellos podrían reprimir fácilmente la mayor parte de estos delitos en acuerdo con el señor Gefe Político y los comisarios regulares. ${ }^{49}$

Días después, otra nota ponía de manifiesto la preocupación por "la poca atención que se presta por los carreros a lo que dispone el artículo 33 del Reglamento de Policía", debido a lo cual, la Sociedad enviaría semanalmente a la jefatura un listado de quienes ejercieran crueldad con animales de tiro o llevasen excesiva carga, indicando el número de carro y la infracción cometida. ${ }^{50}$ Así, los primeros meses de la SPAR estuvieron dedicados a este propósito que, al parecer, obtuvo alguna respuesta positiva con la difusión del reglamento de policía y el cobro de multas a carreros.

Esta preocupación que la SPAR oficializó a mediados de 1871 ya se había hecho presente en la prensa desde inicios de ese año. ${ }^{51}$ Llamativamente, la necesidad de un poder coercitivo legitimado para sus miembros también fue una prioridad para la SAPA. Una de las primeras conquistas de Sarmiento al frente de la protectora fue que el Ejecutivo nacional decretara la colaboración prioritaria de la Policía de la capital con los miembros de la Sociedad a los que se los proveía de una

48. Élida Sonzogni y Gisela Galassi, "De aldea silenciosa a urbe moderna. Los inicios del transporte urbano (1850-1906)", Historia del transporte público de Rosario (1850-2010), coords. Laura Badaloni y Gisela Galassi (Rosario: Editorial Municipal de Rosario, 2011) 25-64.

49. "Cecilio Echeverría al Jefe Político Servando Bayo", 16 de septiembre de 1871. AHPRJM, Rosario, Archivo Jefatura Política de Rosario, t. 1871B.

50. "Cecilio Echeverría al Jefe Político Servando Bayo", 25 de septiembre de 1871. AHPRJM, Rosario, Archivo Jefatura Política de Rosario, t. 1871B.

51. La Capital (Buenos Aires) 19 de enero de 1871; La Capital (Buenos Aires) 21 de junio de 1871; La Capital (Buenos Aires) 22 de julio de 1871. 
tarjeta visada por el jefe de Policía. ${ }^{52}$ Con esta credencial, cualquier miembro de la SAPA que presenciara un acto de maltrato animal violatorio de las ordenanzas vigentes podía ordenar a las fuerzas policiales la detención del infractor. Munida de esta poderosa herramienta, la SAPA porteña incluyó en su haz protector a una gran variedad de especies animales, que iban desde las vacas lecheras hasta los gallos de riña y desde los perros abandonados hasta los peces pescados en la rivera. Sin embargo, en la práctica cotidiana el animal en el que centraba sus esfuerzos era uno solo: el caballo.

Antes que nada, es importante recordar que la SAPA tenía su radio de acción directa dentro de los límites de la ciudad de Buenos Aires, por lo que esto marcaba una primera delimitación de las especies animales que podían ser efectivamente protegidas por ella; sin embargo, la protectora porteña siempre manifestó una clara vocación expansionista en el país y la región (de hecho, su nombre es Sociedad Argentina Protectora de los Animales). Por lo demás, en cada informe anual societario se detallaban con bastante precisión los actos proteccionistas que habían sido ejecutados por los asociados, más allá de que este número no deba ser considerado el definitivo, ya que se pueden leer reiteradas quejas de los distintos secretarios acerca de la cantidad de casos proteccionistas que fueron realizados, pero no comunicados por los socios.

Con base en estas estadísticas, se puede ver un claro predominio de la tutela hacia los equinos por sobre el resto. En efecto, los casos de protección que tienen como objeto a los caballos muestran cifras que oscilan entre el $72 \%$ y el $97 \%$ del total, según los años a los que correspondan. ${ }^{53} \mathrm{El}$ porcentaje restante se lo dividen entre bovinos, aves, perros, gatos y categorías residuales del tipo "otras protecciones". No está de más recordar que para ese entonces casi todo el transporte de la época, tanto público como privado, era realizado en la ciudad con base en la tracción a sangre.

Algunas otras medidas de la protectora ratifican esta predilección, como cuando, en 1883, se intercedió ante el gerente de la compañía de tramways de Buenos Aires para que los caballos llevaran herraduras con tacos de acero, tal como imponían las prácticas seguidas en Inglaterra y Estados Unidos. También fue el caso de la ambulancia que se le encargó a la protectora de Nueva York y que fue gran motivo de orgullo societario, tanto que, a partir de 1886, todos los informes anuales eran precedidos de un dibujo en el que aparecían dos hombres cargando un caballo maltrecho en la celebrada ambulancia de la SAPA (Figura 2).

En los últimos años, los estudios de la antropóloga María Carman han puesto de relieve la opresión similar ejercida sobre caballos y carreros que trabajan con

\section{SAPA, "Decimoséptimo Informe" 41.}

53. Según surge del informe de 1896 , solo el $28 \%$ de los casos de protección registrados no se refieren específicamente a caballos, aunque por la fórmula genérica podrían incluirlos también. Véase SAPA, "Decimoquinto informe anual" (Buenos Aires, 1896) 12-13. Por su parte, en 1888 se registraron 430 casos de protección, de los cuales solo 12 (3\%) no aludían puntualmente a caballos, véase SAPA, "Séptimo informe" (Buenos Aires, 1888) 16-17. 
Figura 2. El gran orgullo de la SAPA, la ambulancia para animales solicitada a la Protectora de animales de Nueva York

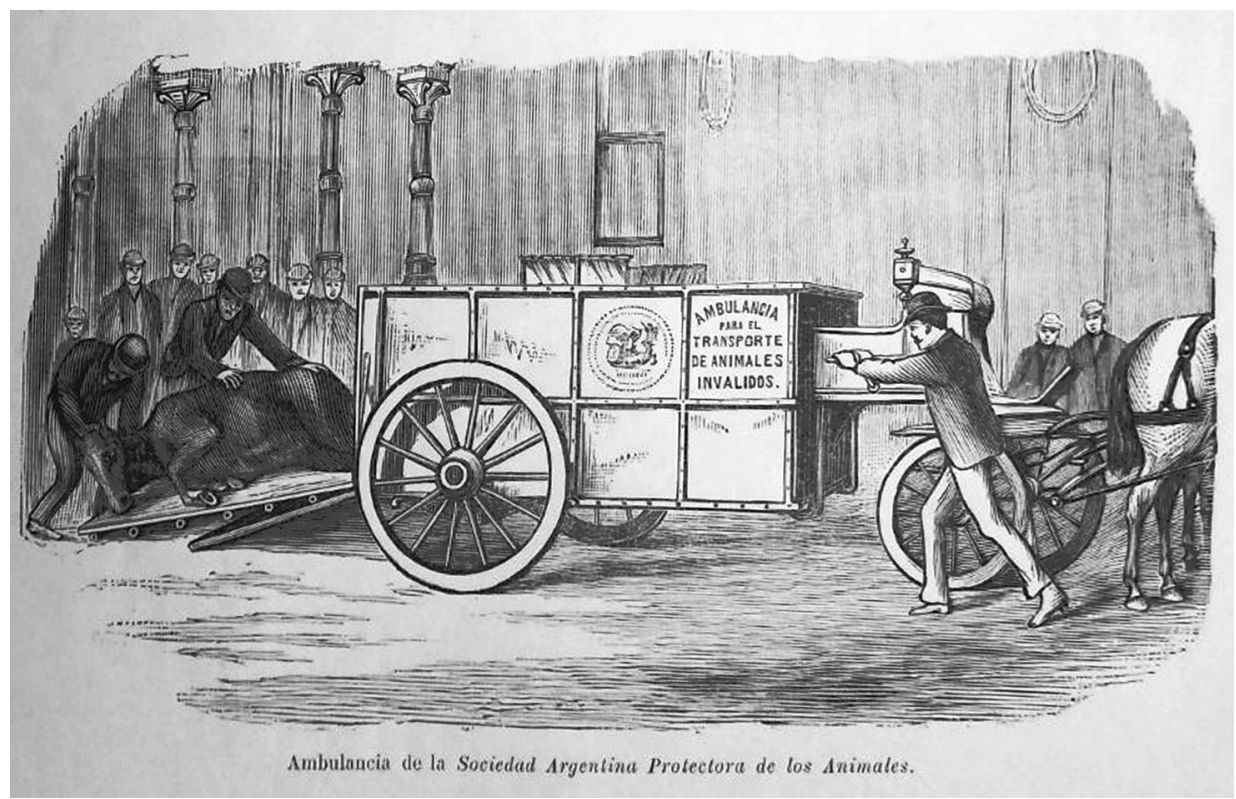

Fuente: SAPA, "Sexto informe anual” (Buenos Aires, 1887) 3.

base en la tracción a sangre por parte de los movimientos proteccionistas en la actualidad. ${ }^{54}$ Carman señala un proceso de "biologización de los maltratadores" (bestias que maltratan a pobres animales), en paralelo a uno de "humanización de los animales" (seres sintientes). Si bien los argumentos de hoy en día no pueden extrapolarse a los vertidos por los proteccionistas del siglo XIX, existe cierta línea de continuidad que estigmatiza casi en los mismos términos a los carreros como bestias, como queda de manifiesto en el epígrafe de este apartado.

En contraposición, resulta interesante la perspectiva en la que el historiador Jason Hribal ubica, desde los siglos XVIII y XIX, a los caballos como fuerza de trabajo, al igual que personas e incluso máquinas: en el caso de los animales, no se reclamaba por su supresión, sino por prevenir el maltrato. ${ }^{55}$ Además, los animales eran considerados como parte de la clase trabajadora porque ejercían ciertas acciones de "resistencia" ante su explotación.

\section{Carman.}

55. La tesis de Jason Hribal sostiene que no sería coincidencia la simultaneidad entre la aparición del movimiento en pos de los derechos animales, en la Inglaterra de los siglos XVIII y XIX, con la formación de la clase trabajadora: analiza ambos movimientos como respuesta a la creciente explotación como fuerza de trabajo en los inicios de la era industrial. Jason Hribal, “'Animals are Part of the Working Class': A Challenge to Labor History”, Labor History 44.4 (2003): 435-453; Jason Hribal, "Animals are Part of the Working Class Reviewed”, Borderlands 11.2 (2012): 1-37. 
Con base en lo examinado sobre ambas sociedades protectoras, este trabajo se arriesga a indicar que la preocupación hacia los caballos, como hacia los toros, además de contener argumentos éticos y pedagógicos basados en el respeto y la compasión por los animales, trasuntaría un interés más enfático de evitar espectáculos desagradables y de crueldad en plenos cascos céntricos de las ciudades, lo que podría asimilarse con la exclusión de la violencia ejercida dentro de los mataderos, que por esos mismos años eran reubicados en los extramuros.

\section{A modo de cierre}

Varios fueron los desafios a enfrentar al emprender esta suerte de ejercicio comparativo entre las dos primeras sociedades protectoras que conoció el país. Mientras que la SAPA cuenta con estudios previos, su homóloga rosarina no tiene investigaciones de envergadura, y el acervo documental conservado para ambas sociedades es disímil en cantidad y calidad.

Respecto a la SPAR, algunos datos dispersos indican que continuó en actividad avanzados los años. En 1890, organizó un concurso infantil de composiciones ${ }^{56}$ inspirado en los certámenes organizados por sociedades protectoras en Europa y en la misma Buenos Aires. Asimismo, un informe de 1916-1918, por entonces bajo la presidencia de Jorge H. French, mencionaba el nombramiento de agentes honorarios en departamentos del interior de la provincia de Santa Fe, lo cual permite pensar en una multiplicación de entidades con fines similares. ${ }^{57}$

Esta proliferación de protectoras de animales se puede observar también en el plano nacional, con un marcado liderazgo por parte de la SAPA, la cual se atribuyó la conducción del proteccionismo en Argentina, no solo desde su nombre, sino también por el hecho de que concentró grandes esfuerzos en gestionar sucursales en el resto del país. Esto se concretaba a través de gestiones directas, como en los casos de las sucursales de Mendoza ${ }^{58}$ o de la provincia de Buenos Aires con sede en La Plata, ${ }^{59}$ y también mediante un rol un tanto más indirecto en el que colaboraba en la constitución de las nuevas sociedades, sin abandonar su papel paternalista, como en los casos de los intentos de formación de protectoras en Santa Fe y Corrientes, ${ }^{60}$

56. Sociedad Protectora de Animales de Rosario (SPAR), Compasión para los animales. Primer concurso infantil. Sus antecedentes. Composiciones premiadas en acto público celebrado el 9 de julio de 1890 (Rosario: Imprenta y Encuadernación La Industrial, 1890).

57. "Sociedad Protectora de los Animales Informe del Presidente años 1916-1918”, encuadernación casera. Allí se señala que desde 1893 "se había adoptado la costumbre de hacer una memoria que abarque un periodo de dos o tres años, y aunque he seguido esa costumbre, opino que, en adelante, convendría presentarla cada año".

58. SAPA, "Decimocuarto informe anual" (Buenos Aires, 1895).

59. SAPA, "Séptimo informe".

60. SAPA, "Quinto informe anual” (Buenos Aires, 1886). 
o incluso a través de la "influencia decisiva que ha ejercido para la organización de una congénere en Montevideo". ${ }^{61}$

Esta dirección nacional luego se vería convalidada principalmente por el que sería el logro societario más importante de la SAPA, la ley 2786 sobre maltrato animal, ${ }^{62}$ que luego sería conocida como la ley Sarmiento, pese a haber sido sancionada tres años después de la muerte del expresidente de la nación y con base en un texto redactado por Albarracín. Esta ley consolidó la reputación de la SAPA ${ }^{63}$ y consagró el predominio nacional de la protectora porteña en las siguientes décadas, que solo se vería jaqueado a comienzos del siglo XX por otra protectora creada a partir de un desmembramiento de la SAPA, la cual se daría a conocer como "La Sarmiento", en un claro mensaje de rechazo a la gestión de Albarracín. ${ }^{64}$

Un eje detectado en esta investigación es la existencia de una suerte de núcleo regional de protectoras entre Buenos Aires, Rosario y Montevideo en función de la confluencia entre metodismo, masonería y protección animal. Sobre el primer punto, es posible señalar que en 1867 se produjo la primera predicación metodista en idioma castellano y a partir de allí la misión comenzó a expandirse territorialmente, estableciéndose en tres ciudades cabeceras: Buenos Aires, Rosario y Montevideo. Los lazos con esta última se observan en la correspondencia intercambiada entre Cecilio Echeverría y amigos uruguayos (especialmente con Joaquín Noguera durante 1871 y 1872), y la probabilidad de vínculos masones con Montevideo. ${ }^{65}$ Las referencias de la prensa indican que los toreros llegados a Rosario para las corridas venían de Montevideo ${ }^{66} \mathrm{y}$, sumado a esto, como ya se indicó, los dos empresarios que obtuvieron la primera concesión de la provincia de Santa Fe para realizar las corridas eran montevideanos. Algo similar ocurrió en Buenos Aires en 1885, cuando se intentó sin éxito realizar una corrida de toros con "seis bravos [...] y una

61. SAPA, "Séptimo Informe" 6.

62. El derrotero de la que sería la ley 2786 comenzó en 1883 a instancias de Sarmiento y finalizó en 1891 con varias modificaciones. Su éxito se debió a la insistencia de Ignacio Albarracín, quien, año tras año, presionó al Congreso Nacional para que impusiera su tratamiento y aprobación, tarea que le infundió grandes energías, principalmente por la falta de interés del Poder Legislativo y de la prensa en general.Véase Gonzalo Luis Corti, "El rol de la Sociedad Argentina Protectora de los Animales en el impulso y sanción de la ley 2.786 de maltratamiento animal (1882-1891)" (Ponencia, XI Jornadas Internacionales de Jóvenes Investigadores en Historia del Derecho, Universidad de Buenos Aires, 2019).

63. SAPA, "Undécimo Informe".

64. Urich.

65. No existe demasiada bibliografía sobre la masonería en clave regional. Los trabajos de Paula Saguier desde la óptica del protestantismo abordan algo de esto, y para Uruguay puede verse Dévrig Mollès, "Exiliados, emigrados y modernizadores: el crisol masónico euro-argentino (Europa-Río de la Plata, 1840-1880)", La masonería española: represión y exilios, t. 1, coord. José Antonio Ferrer Benimeli (Zaragoza: Centro de Estudios Históricos de la Masonería Española, 2010) 47-70. Agradecemos a Mario Etchechury esta referencia sobre Uruguay.

66. La Capital (Buenos Aires) 9 de enero de 1872. 
cuadrilla de toreros" que se traerían de Montevideo. ${ }^{67}$ Por otra parte, la primera Sociedad Protectora de Animales de Montevideo fue más o menos coincidente con la de Buenos Aires, al fundarse en 1888, bajo la presidencia de Jacinto Albistur, ${ }^{68}$ en ese mismo año, se prohibieron las corridas de toros en todo el país a partir de $1890 .^{69}$ Estos indicios, si bien no permiten extraer conclusiones, marcarían cierta triangulación de estas tres ciudades, lo que insertaría al proteccionismo animal en una clave regional, a partir de la circulación y rotación de intereses comerciales (empresas para las corridas de toros), relacionales (opiniones privadas vertidas en correspondencia, masonería), religiosos (misión metodista) e influencias mutuas en los inicios de las sociedades protectoras.

Otro de los puntos para destacar es el carácter exclusivamente urbano del accionar de ambas sociedades protectoras. En el rango de especies protegidas, solo la SAPA tuvo un discurso más abarcador, aunque en general no era amplio: los animales de tiro y los toros fueron los protagonistas de las acciones desarrolladas por ambas protectoras. El origen de dicha protección no remitía tanto a una empatía por el sufrimiento que vivían — cabe recordar que en el mismo momento se daban campañas de envenenamiento de perros callejeros-, sino al impacto público de los espectáculos que los envolvían: las corridas de toros y los maltratos en plenas calles céntricas no pasaban desapercibidos y la colaboración de los agentes policiales se volvía crucial para el éxito de las medidas propuestas. ${ }^{70}$ Estos son algunos ejes que intentan abrir el tema y el panorama hacia el resto de las experiencias provinciales.

\section{Fuentes}

\section{Manuscritas}

Archivo Histórico Provincial “Dr. Julio Marc”, Rosario (AHPRJM)

\section{Documentos manuscritos}

Expediente penal

Archivo Jefatura Política de Rosario

Archivo General de la Provincia de Santa Fe, Santa Fe (AGPSF)

Gobierno

67. SAPA, "Cuarto informe" 34.

68. "Los estatutos fijaban así los fines de la Sociedad: 'Prevenir la crueldad para con los animales; propender, por todos los medios posibles, a la estimación y buen trato de los mismos; propender a la fundación de una escuela de veterinaria; estimular, por medio de la prensa, a los dueños de animales que se hagan meritorios en su cuidado". "Gobierno de Tajes (1886-1890)", Anales de la Universidad (Montevideo) 1934: 480.

69. Diego Bracco, "Apuntes para la historia de la tauromaquia en Uruguay", Revista de Estudios Taurinos 22 (2006): 203-247; Diego Bracco, "Historia de la tauromaquia en Uruguay (II)", Revista de Estudios Taurinos 25 (2008): 77-124.

70. Agulhon señala como foco de las argumentaciones proteccionistas en el París del siglo XIX tres clases: una económica, de resguardo de los caballos como bien material; otra higienista, por las malas condiciones de transporte, y la pedagógica-moral, por el mal ejemplo de crueldad frente a los niños. 


\section{Impresas}

Diarios de Sesiones de la Cámara de Diputados de la Nación. Buenos Aires: Congreso de la Nación, 1891.

Ordenanza del 20 de abril de 1888. Buenos Aires: Publicación Oficial, Cía. Sudamericana de Billetes de Banco, 1890.

Ordenanza del 14 julio 1874. Buenos Aires: Publicación Oficial, Cía. Sudamericana de Billetes de Banco, 1890.

Reglamento de Policía. Registro Oficial de la provincia de Santa Fe. Tomo 4. Santa Fe: Tipografia de la Revolución, 1889.

Sarmiento, Domingo Faustino. Facundo o Civilización i Barbarie en las Pampas argentinas. París: Hachette y Cía., 1874.

Sociedad Argentina Protectora de los Animales (SAPA). "Bases y reglamento de la Sociedad Protectora de los Animales". Buenos Aires, 1881.

—. "Segundo informe anual". Buenos Aires, 1883.

—. "Cuarto informe anual”. Buenos Aires, 1885.

—. "Quinto informe anual”. Buenos Aires, 1886.

—. "Sexto informe anual”. Buenos Aires, 1887.

—. "Séptimo informe anual". Buenos Aires, 1888.

. "Noveno informe anual". Buenos Aires, 1890.

—_. "Décimo informe anual". Buenos Aires, 1891.

—. "Undécimo informe anual”. Buenos Aires, 1892.

—. "Decimocuarto informe anual". Buenos Aires, 1895.

—_. "Decimoquinto informe anual". Buenos Aires, 1896.

. "Decimoséptimo informe anual”. Buenos Aires, 1898.

Sociedad Protectora de Animales de Rosario (SPAR). Compasión para los animales. Primer concurso infantil. Sus antecedentes. Composiciones premiadas en acto público celebrado el 9 de julio de 1890. Rosario: Imprenta y Encuadernación La Industrial, 1890.

\section{Periódicos y revistas}

Anales de la Universidad (Montevideo) 1934.

La Cabrionera (Rosario) 1871.

La Capital (Buenos Aires) 1871-1872.

\section{Internet}

https://www.lacapital.com.ar/ (2020) 


\section{Bibliografía}

Agulhon, Maurice. "Le sang des bêtes. Le problème de la protection des animaux en France au XIXème siècle”. Romantisme 11.31 (1981): 81-110.

Amestoy, Norman Rubén. "El reformismo social metodista en el Río de la Plata y sus raíces ideológicas”. Cuadernos de Teología 20 (2001): 343-360.

. "Sociedades metodistas y pensamiento científico en el Río de la Plata (1867-1901)". Estudios de Historia Moderna y Contemporánea (2009): 1-25. . "Thomas Wood y su presencia en el Río de la Plata". Invenio. Revista de Investigación Académica 12.22 (2009): 29-41.

Barrán, José Pedro. Historia de la sensibilidad en el Uruguay. Tomo 2. Montevideo: Facultad de Humanidades y Ciencias / Ediciones de la Banda Oriental, 1990.

Berros, María Valeria y otros. "La mirada jurídica sobre los animales: un análisis de su estatuto en el derecho privado argentino". Revista de Derecho de La Pontificia Universidad Católica de Valparaíso 48.1 (2017): 79-101.

Bracco, Diego. "Apuntes para la historia de la tauromaquia en Uruguay". Revista de Estudios Taurinos 22 (2006): 203-247.

. "Historia de la tauromaquia en Uruguay (II)". Revista de Estudios Taurinos 25 (2008): 77-124.

Bruno, Daniel. "Abordaje y periodización para una historia del metodismo en Argentina”. Revista Evangélica de Historia 7 (2012): 11-44.

Carman, María. Las fronteras de lo humano: cuando la vida humana pierde valor y la vida animal se dignifica. Buenos Aires: Siglo XXI Editores, 2017.

Cecchi, Ana. "La ciudad timbera: juego, Estado y cultura en Buenos Aires, 18911932”. Tesis de doctorado en Historia, Universidad de San Andrés, 2016.

Corte Caballero, Gabriela Dalla. Lealtades firmes. Redes de sociabilidad y empresas: la “Carlos Casado, S. A." entre la Argentina y el Chaco paraguayo (1860-1940). Madrid: Consejo Superior de Investigaciones Científicas, 2009.

Corti, Gonzalo Luis. "El rol de la Sociedad Argentina Protectora de los Animales en el impulso y sanción de la ley 2.786 de maltratamiento animal (18821891)". Ponencia, XI Jornadas Internacionales de Jóvenes Investigadores en Historia del Derecho, Universidad de Buenos Aires, 2019.

Cragnolini, Mónica B. "Extraños animales: la presencia de la cuestión animal en el pensamiento contemporáneo". Revista Latinoamericana de Estudios Críticos Animales 2 (2014): 15-33.

Cuesta, Eduardo Martín. "Precios y salarios en Buenos Aires durante la gran expansión (1850-1914)”. Revista de Instituciones, Ideas y Mercados 56 (2012): 159-79.

Cutolo,Vicente Osvaldo. Nuevo diccionario biográfico argentino (1750-1930). Buenos Aires: Elche, 1969.

Di Stefano, Roberto y otros. De las cofradías a las organizaciones de la sociedad civil. Historia de la iniciativa asociativa en Argentina, 1776-1990. Coords. Elba 
Luna y Elida Cecconi. Buenos Aires: Edilab, 2002.

Elias, Norbert. El proceso de la civilización: investigaciones sociogenéticas y psicogenéticas. México: Fondo de Cultura Económica, 2015.

Falcón, Ricardo. "La larga batalla por el carnaval: la cuestión del orden social, urbano y laboral en el Rosario del siglo XIX”. Anuario de la Escuela de Historia. Segunda Época 14 (1990): 207-226.

Funes Monzote, Reinaldo. "Facetas de la interacción con los animales en Cuba durante el siglo XIX: los bueyes en la plantación esclavista y la Sociedad Protectora de Animales y Plantas”. Signos Históricos 8.16 (2006): 80-110.

González Bernaldo de Quirós, Pilar. "Sociabilidad y regímenes de lo social en sociedades post-imperiales: Una aproximación histórica a partir del caso argentino durante el largo siglo XIX”. Sociabilidades en la historia: actas del VIII Congreso de Historia Social de España, Tarragona, 16 al 18 de abril de 2015. Coords. Santiago Castillo y Montserrat Duch i Plana. Madrid: Catarata, 2015.

Guerrero, Gilda. "Toros en Buenos Aires". Todo es Historia 26 (1969): 42-49.

Holt, Richard. Sport and the British. A modern history. Oxford: Oxford University Press, 2009.

Hribal, Jason. “'Animals Are Part of the Working Class': A Challenge to Labor History". Labor History 44.4 (2003): 435-453.

. "Animals Are Part of the Working Class Reviewed". Borderlands 11.2 (2012): 1-37.

Kelch, Thomas G. “A Short History of (Mostly) Western Animal Law. Part I”. Animal Law Review 19.23 (2012): 23-62.

Mauro, Diego A. "Procesos de laicización en Santa Fe (Argentina): 1860-1900. Consideraciones sobre la "Argentina liberal y laica",. Revista de Indias 74.261 (2014): 539-560.

Micheletti, María Gabriela. "Entre gauchos y gringos. Costumbres nacionales y extranjeras en Santa Fe (1880-1900)". Temas de Historia Argentina y Americana 16 (2010): 227-257.

Mollès, Dévrig. "Exiliados, emigrados y modernizadores: el crisol masónico euroargentino (Europa-Río de la Plata, 1840-1880)". La masonería española: represión y exilios. Tomo 1. Coord. José Antonio Ferrer Benimeli. Zaragoza: Centro de Estudios Históricos de la Masonería Española, 2010.

Olgo Ochoa, Pedro. "La riña de gallos, seducción de ricos y pobres". Todo es Historia 29 (1969): 28-36.

Seiguer, Paula. "Jamás he estado en casa". La iglesia Anglicana y los ingleses en la Argentina. Buenos Aires: Editorial Biblios, 2017.

Sonzogni, Élida y Gisela Galassi. "De aldea silenciosa a urbe moderna. Los inicios del transporte urbano (1850-1906)". Historia del transporte público de Rosario (1850-2010). Coords. Laura Badaloni y Gisela Galassi. Rosario: Editorial Municipal de Rosario, 2011.

Stone, Christopher. “¿Los árboles deberían tener legitimidad procesal? Hacia un 
reconocimiento de los derechos legales de los objetos naturales". Derecho ambiental y justicia social. Garrett Hardin y otros. Bogotá: Siglo del Hombre Editores / Pontificia Universidad Javeriana, 2009.

Tallon, Guillermo. Historia del Metodismo en el Río de la Plata, 1836-1936: un panorama histórico de la Iglesia Metodista Episcopal en la Argentina, Uruguay y Paraguay, durante los cien años transcurridos desde su iniciación hasta nuestros días. Buenos Aires: Imprenta Metodista, 1936.

Urich, Silvia. Los perritos bandidos: la protección de los animales de la Ley Sarmiento a la Ley Perón. Temperley:Tren en Movimiento, 2015.

Zaffaroni, Eugenio Raúl. La Pachamama y el humano. Buenos Aires: Ediciones Madres de Plaza de Mayo, 2011. 